\title{
The incidence of disabilities in Hansen's disease after the commencement of chemotherapy
}

\author{
RICHARD F KEELER \& MARGARET A RYAN \\ Hansen's Disease Control Unit, Ministry of Health, Port of Spain, \\ Trinidad and Tobago, West Indies
}

Received for publication 28 November 1979

\begin{abstract}
Summary Of 529 patients diagnosed as having Hansen's disease during the period 1 January 1971 to 31 December 1976 in the tropical twin island nation of Trinidad and Tobago, $473(89 \%)$ were free of disabilities at the time of diagnosis. Of these, $335(71 \%)$ were re-evaluated in 1978 in an attempt to determine the incidence of disabilities during the first few years of chemotherapy. Only two patients $(0.6 \%)$ in this group were found to have developed disabilities. We concluded that disability occurs very infrequently in Trinidad after the diagnosis of Hansen's disease and the commencement of chemotherapy.
\end{abstract}

\section{Introduction}

One of the commonly expressed fears of patients who have Hansen's disease has been that, sooner or later, disabilities will develop. We could understand their concern, as we have seen many patients with disabilities. Yet, from a theoretical standpoint, it seemed that disabilities did not need to occur. In addition, from our observation of patients diagnosed in the 1970s, we rarely saw disabilities developing among them. With adequate treatment to kill the Mycobacterium leprae, and to suppress or rapidly reverse any inflammatory episodes such as acute neuritis, we felt that disabilities should be preventable. Minimal information is available on this in the literature.

After several years of observing that the occurrence of disabilities was uncommon among our patients who are on chemotherapy we decided to conduct a follow-up study on all patients diagnosed with Hansen's disease in Trinidad and Tobago during the years 1971 to 1976.

Our objectives were to find: (1) the incidence of disabilities among those who were free of disabilities at the time of diagnosis, (2) what changes occurred in those with disabilities at the time of diagnosis, and (3) what relationship 
there might be between regularity of treatment and the development of or the regression of disabilities. This paper deals primarily with the first objective.

\section{Methods}

From early 1971 detailed information was obtained and recorded at the time of diagnosis for each newly diagnosed patient with Hansen's disease. This included an evaluation by our physiotherapist. When disabilities were found, appropriate measurements were obtained and tests were performed to establish a baseline from which future changes could be measured.

During 1978 our physiotherapist re-evaluated as many patients as possible of those diagnosed from 1 January 1971 to 31 December 1976.

We chose 31 December 1976 as our cut-off date in order to provide a minimum of at least one year on chemotherapy before re-evaluating a patient's condition.

Patients were examined for loss of protective sensation in hands and feet, nasal collapse, lagophthalmos, visual deficit, clawing and contracture of fingers, loss of opposition of thumb, absorption of digits, claw toes, wrist drop, foot drop and plantar ulcers. The World Health Organization classification of disabilities using five grades was used. A separate sheet was used for the recording of each patient's findings.

\section{Results}

Of the 529 patients diagnosed as having Hansen's disease between 1 January 1971 and 31 December 1976, fifty-six (11\%) initially had disabilities, leaving 473 patients $(89 \%)$ free of disabilities at time of diagnosis.

Of these 473 disability free patients, $335(71 \%)$ were re-examined in 1978.

Of the 335 patients who were re-examined in 1978, only $2(0.6 \%)$ had developed any disabilities subsequent to the commencement of chemotherapy (see Table 1).

One of these was a female (identification No S-71-25), who was four and a half years old when diagnosed on 3 June 1971 with the dimorphous-tuberculoid (BT) type of Hansen's disease. On 12 July 1976 she was first noted to have non-tender left ulnar nerve enlargement, and by 11 October 1976 had mobile clawing of the left second to fifth fingers plus sensory deficit in the left fifth finger. Further deterioration in the function of all the lumbrical muscles was evident upon examination on 23 January 1978.

As measured by clinic attendance, her overall drug intake had been irregular (see Table 2).

The other 44 patients diagnosed in 1971 who were initially free of disabilities 
Table 1. Disability status of Hansen's disease patients diagnosed in Trinidad and Tobago 1971-1976

\begin{tabular}{lcc}
\hline \multicolumn{1}{c}{ Status } & No & Per cent \\
\hline Total diagnosed & 529 & $(100)$ \\
With disabilities & 56 & $(11)$ \\
Without diabilities & 473 & $(89)$ \\
Not re-examined in 1978 & 138 & $(29)$ \\
Re-examined in 1978 & 335 & $(71)$ \\
Found without diabilities in 1978 & 333 & $(99.4)$ \\
Found with disabilities in 1978 & 2 & $(0.6)$ \\
\hline
\end{tabular}

Table 2. Regularity of anti-Hansen's chemotherapy intake in patient S-71-25 from 1971 to $1975^{*}$

\begin{tabular}{cc}
\hline Year & $\begin{array}{c}\text { Regularity } \\
(\%)\end{array}$ \\
\hline 1971 & 87 \\
1972 & 65 \\
1973 & 83 \\
1974 & 65 \\
1975 & 25 \\
\hline${ }^{*} 75 \%$ or greater is considered to be regular \\
treatment (ie, the collection of $75 \%$ or more of \\
prescribed drugs).
\end{tabular}

Table 3. Cohorts* of Patient S-71-25 Taking Anti-Hansen's Chemotherapy Regularly, 1971 to 1975 :

\begin{tabular}{lcc}
\hline Year & $\begin{array}{c}\text { Number on } \\
\text { regular treatment }\end{array}$ & $\begin{array}{c}\text { Percent on } \\
\text { regular treatment }\end{array}$ \\
\hline 1971 & 30 & 70 \\
1972 & 26 & 60 \\
1973 & 20 & 45 \\
1974 & 18 & 40 \\
1975 & 15 & 35 \\
\hline
\end{tabular}

* Other Hansen's Disease patients diagnosed in 1971

and were re-examined in 1978 also had a poor record of treatment regularity (see Table 3).

Over the same five and a half year period only twelve of these 44 (27\%) had been consistently regular in taking their treatment.

The other patient with a disability was a male (identification number D-76-65) who was sixty-seven years old when diagnosed on 17 November 1976 with the dimorphous (BB) type of Hansen's disease. At the time of diagnosis he had a non-tender moderately enlarged right ulnar nerve. On 14 January 1977 
he was first noted to have slight motor weakness in muscles supplied by the right ulnar nerve, but no clawing. At this time he had ulnar pain. He was taking medication regularly during these first two months. 37 out of $59(63 \%)$ other Hansen's disease patients also diagnosed in 1976 who were free of disabilities had taken treatment regularly during 1976.

Of these 138 patients who were not re-examined investigation revealed that 78 had been discharged from the clinics as cured, 32 could not be located, 19 had migrated and 9 had died (see Table 4).

Table 4. Disability-free patients not re-examined in 1978

\begin{tabular}{lr}
\hline Reason & No \\
\hline Discharged & 78 \\
Lost & 32 \\
Emigration & 19 \\
Death & 9 \\
TOTAL: & 138 \\
\hline
\end{tabular}

By examining the records we found that none of the 78 discharged patients had disabilities at the time of their release. Nor did any of the 9 who died have any disabilities when last examined.

Only one of the emigrants developed a disability prior to leaving the country. This was a male (identification number M-73-24), who was 15 years old at the time of his diagnosis on 28 March 1973, and developed a weakness in dorsiflexion of his right foot in late May 1973. He had the dimorphous (BB) type of Hansen's disease, attended clinic irregularly and took medication only $50 \%$ of the time between diagnosis and the onset of this disability. No peripheral nerves were noted to have been enlarged or tender at the time of diagnosis. When he left the country in February 1977 he had a right footdrop (grade 2 disability). 79 per cent of his disability-free cohorts maintained regular chemotherapy during 1973.

Thus a total of three patients out of 473 (less than 1\%) are known to have developed disabilities since the commencement of anti-leprosy chemotherapy. This is in sharp contrast to the 56 out of 529 patients (11\%) who had disabilities prior to chemotherapy.

\section{Discussion}

Although the numbers are too small to be statistically significant, it is of interest that all 3 patients who developed disabilities were in the dimorphous (borderline) portion of the Hansen's disease spectrum.

Over this six-year period of time the number of newly diagnosed patients in 
each part of the Hansen's disease spectrum were: indeterminate 20, tuberculoid 313, dimorphous 154 and lepromatous 42 . Thus if patients in each type have the same probability of developing disabilities we would expect the majority of disabilities to develop in tuberculoid patients. Instead, all disabilities developed in dimorphous patients during the period under observation (see Table 5).

Table 5. Comparison of observed and expected incidence of disability by type of Hansen's disease among patients diagnosed in Trinidad and Tobago 1971-1976

\begin{tabular}{lcc}
\hline \multicolumn{1}{c}{ Type } & Observed & Expected \\
\hline Indeterminate & 0 & 0.1 \\
Tuberculoid & 0 & 1.8 \\
Dimorphous & 3 & 0.9 \\
Lepromatous & 0 & 0.2 \\
TOTAL & 3 & 3 \\
\hline
\end{tabular}

It is also of interest that 2 of the 3 patients were irregular in taking their treatment prior to the development of disabilities. The one who was on regular treatment had neural involvement at the time of diagnosis as indicated by enlargement of the ulnar nerve.

Except for one patient who had evidence of neural involvement at the time of diagnosis and later developed a disability, none of the 143 patients who consistently took treatment regularly among the 335 examined in 1978 developed disabilities. However, only two patients developed disabilities out of the remaining 192 patients who were irregular in their drug intake.

With a significant proportion of those patients who were free of disabilities being irregular in taking treatment, one wonders why more disabilities did not occur. One possible explanation may be found in the treatment schedule of the 1970s when daily drug intake (Dapsone $50 \mathrm{mg}$ ) was commenced instead of the former $100 \mathrm{mg}$ once to thrice per week. In 1978 we increased our standard dosage of Dapsone to $100 \mathrm{mg}$ daily. Adequate blood levels of drugs are more likely to be maintained even when occasional doses are not taken when on a daily regimen than when on a less frequent schedule.

Two of the 3 patients who developed disabilities developed them within two months of the commencement of chemotherapy. One wonders whether there is a causal relationship, or if neuropathological changes were already occurring at the time of diagnosis which progressed in spite of chemotherapy. The 67 year old patient, in particular, seems to fit into this latter category.

On the basis of this study we have concluded that minimal disability (less than $1 \%$ ) occurs in Hansen's disease during the first few years of chemotherapy. 
Additional studies are necessary to clarify the various factors in chemotherapy that are responsible for preventing disabilities.

\section{Acknowledgments}

The authors wish to thank the Ministry of Health in Trinidad and Tobago for permission to publish this paper. We also thank Dr Felton Ross (American Leprosy Missions) for his valuable advice and encouragement, $\mathrm{Mr}$ Adrian Lambourne, Statistician (Caribbean Epidemiology Centre), for his helpful assistance in the presentation of our data and Miss Wendy Akal for her typing of the manuscript. 